International Journal of Tropical Medicine 6 (2): 39-43, 2011

ISSN: $1816-3319$

(C) Medwell Journals, 2011

\title{
Rift Valley Fever Virus Large (L) RNA Segment as a Target Gene for Direct Detection of the Virus in Acute Phase Sera Using RT-PCR
}

\author{
Afraa T.M. Elata and Imadeldin E. Aradaib \\ Department of Clinical Medicine, Faculty of Veterinary Medicine, \\ University of Khartoum, Sudan
}

\begin{abstract}
The Large (L) RNA segment of Rift Valley Fever (RVF) virus (RVFV) was evaluated for detection of the virus in serum samples from acute hemorrhagic fever cases using RT-PCR. The RT-PCR produced a 342 base pair (bp) from RVF RNAs samples extracted from sera from infected humans. However, the RT-PCR assay did not amplify the specific 342 bp product from RNAs extracted from closely related hemorrhagic fever viruses including Crimean Congo Hemorrhagic Fever Virus (CCHFV), Dengue virus, total RNA extracted from non infected vero cells. The described RT-PCR provides rapid, sensitive and specific method for detection of RVFV RNA directly in human sera sampled during acute phase of the disease.
\end{abstract}

Key words: Epidemiology, viral hemorrhagic fevers, RVFV, L segment, RT-PCR, Sudan

\section{INTRODUCTION}

Rift Valley Fever (RVF) Virus (RVFV) is a member of the Phlebovirus genus in the family Bunyaviridae. The virus has a single stranded RNA genome which is composed of a Large (L), a Medium (M) and a Small (S) segment (Giorgi, 1996; Garcia et al., 2001). The Large (L) segment codes for the viral polymerase which is necessary for virus replication. The virus was first isolated in 1930 in the Rift Valley province, Kenya associated with large epidemics in domestic ruminants and humans (Daubney et al., 1931). The virus is transmitted to livestock and humans by the bites of infected mosquitoes of the genus Aedes or exposure to infected human or animal tissues (Meegan and Bailey, 1989).

RVF outbreaks have been reported in many African countries including Kenya, Somalia, Tanzania, Egypt, Senegal, Mauritania, Nigeria and South Africa (Arthur et al., 1993; Olaleye et al., 1996; Sall et al., 1998; Sall et al., 1999, 2001). In 2000, RVF cases were confirmed in Saudi Arabia and Yemen marking the first reported occurrence of the disease outside the Africa (Shoemaker et al., 2002; Ahmad, 2000). In Sudan, the virus was first isolated from infected calves during an out break of the disease in Kosti, White Nile State (Eisa and Obeid, 1977). Subsequently, the virus was isolated from sporadic cases of infected calves in Hilat Koko (Eisa et al., 1980). Recently, out breaks of the disease were reported in different states of Sudan including Gazeera, Kassala,
Khartoum, River Nile, Sinnar and White Nile (Elageb, 2010). RVFV is currently diagnosed by serology, virus isolation and molecular based techniques (Shope et al., 1980; Meegan et al., 1987; Garcia et al., 2001; Sall et al., 2001; Jansen van Vuren et al., 2007). Serological assays are complicated by cross reactions and usually require some times for antibodies to be produced by the susceptible host. Since RVFV is considered as a bioterrorism agent, working with the virus is hazardous and high containment laboratory facilities (BSL-4) are required for handling virus isolation attempts. These limitations encourage the development of reliable, sensitive, inexpensive and rapid methods for detection of the virus genome by molecular based techniques. Sensitive assays are critical to the success of any monitoring program such as prevention and control programs. In previous studies, rapid, sensitive, inexpensive diagnostic assays for detection of RVFV using molecular techniques were developed and evaluated based on different gene segments of the virus (Espach et al., 2002; Ashmaig et al., 2008; Sall et al., 2001; Youssef, 2001; Le Roux et al., 2009). In previous study, a Reverse Transcriptase (RT) Polymerase Chain Reaction (RT-RCR) amplification assays targeting the S-segment of the virus were recently described (Ibrahim et al., 1997; Sall et al., 1999, 2001; Ashmaig et al., 2008). In addition RT-PCR assay was also developed for rapid detection of the virus based on M segment (Salim et al., 2010). It is well known that the $\mathrm{L}$ segment of the virus is highly conserved among cognate genes of RVFV strains.

Corresponding Author: Imadeldin E. Aradaib, Department of Pharmacology and Toxicology, Faculty of Veterinary Medicine, University Khartoum, Sudan 
Therefore, it is suggested that detection of the virus targeting this L segment should enhance rapid diagnosis RVFV and would facilitate differential diagnosis of hemorrhagic fever viruses. In the present investigation, a conventional gel-based RT-PCR assay was developed for direct detection of RVFV in human sera targeting a fragment of the $L$ segment of the virus.

\section{MATERIALS AND METHODS}

Cell culture and virus propagation: The South African vaccine strain of RVFV (Smithburn) was provided by Dr. M. Abdelrazig, Ministry of Animal resource, Sudan. Crimean Congo Hemorrhagic Fever Virus (CCHFV) RNA was extracted from sera of infected patients during a recent nosocomial outbreak of the disease in a rural hospital, West Kordufan, Sudan (Aradaib et al., 2010). Dengue virus RNA was kindly provided by Dr. Abubaker Shazaly, Department of Microbiology, Faculty of Medicine, University Malaya, Malaysia. The RVFV vaccine strains were propagated on confluent monolayers of Vero cells as described previously (Ashmaig et al., 2008). The infectious material was harvested and centrifuged at $1,500 \times \mathrm{g}$ for $30 \mathrm{~min}$ and the supernatant was used for viral RNA extraction.

Collection of blood and serum samples: All samples were collected during the epizootic of RVFV in late fall and early winter of 2007. The most seriously affected areas of the Gezera State and the White Nile State of the Central Sudan were considered in this study. Serum samples, used in this study were collected from acute hemorrhagic fever cases and were kindly provided by Dr. Karsani, the National Medical health laboratory, Sudan. Serum samples and infected cell culture were used for detection of viral genome (L segment) by RT-PCR

Extraction of viral nucleic acid from infected cell culture: Viral RNAs were extracted from the infected cell cultures and serum samples using QIAamp viral RNA kit (QIAamp, $\mathrm{GmHb}$, Germany) as per manufacturer's instructions. Briefly, $140 \mu \mathrm{L}$ of virus suspension or sera were added to $560 \mu \mathrm{L}$ AVL buffer containing carrier RNA into a $1.5 \mathrm{~mL}$ micro-centrifuge tube and mixed by pulse-vortexing for $15 \mathrm{sec}$ followed by incubation at room temperature for $10 \mathrm{~min}$. About $560 \mu \mathrm{L}$ of absolute ethanol were added and mixed by pulse-vortexing for $15 \mathrm{sec}$. About $630 \mu \mathrm{L}$ of the mixture were transferred to QIAamp spin column mounted on $2 \mathrm{~mL}$ collection tube and centrifuged at $6000 \times(8000 \mathrm{rpm})$ for $1 \mathrm{~min}$. The column was then transferred to another collection tube and the other $630 \mu \mathrm{L}$ of the mixture were passed through it. The column was then washed twice with $500 \mu \mathrm{L}$ of washing buffers WB1 and WB2, respectively. Finally, RNAs were carefully eluted by $60 \mu \mathrm{L}$ of buffer AVE equilibrated to room temperature. Viral RNAs and total nucleic acids extracted from Vero cell cultures were quantified using a spectrophotometer at $260 \mathrm{~nm}$ wavelength.

Extraction of viral nucleic acid from serum samples: Extraction of viral nucleic acid from serum samples was performed as described for extraction of RNAs from cell culture supernatnts.

Primer selection: A pair of primers (RV1 and RV2) was selected from the published sequence of the Large segment which codes for Viral polymerase which is required for virus replication (Bird et al., 2008) and used for the synthesis of the PCR amplification product. The primers specific for amplification of RVFV L segment were designed based on multiple sequence alignment of 20 published conserved sequences of the genes using BioEidit software (Carlsbad, CA, USA). Primer RV1 included bases 1701-1720 of the positive sense strand of the L RNA gene (5)-TGT GTC TTT CGC AAT CAA GC(3). RV2 included bases 2084-2103 of the complementary strand: (5)-TGA GGT TTT GGG ATT TCT GG-(3). Using primers RV1 and RV2, the RT-PCR would produce a 384 bp nested PCR product. All primers were synthesized on a DNA synthesizer (Milliigen/Biosearch, a division of MilliporeBurlington, MA) and purified using oligo-pak oligonucleotide purification columns (Glen Research Corporation, Sterling, VA.) as per manufacturer's instructions. Reverse Transcriptase (RT) Polymerase Chain Reaction
(RT-PCR) protocol: A single-tube RT-PCR amplification was carried out using One-Step Access RT-PCR system (QIA-Gen, California, USA). Briefly, a standard $50 \mu \mathrm{L}$ reaction mixture contained in final concentration of $1 \times$ enzyme mix reaction buffer, $5.0 \mu \mathrm{L}$ of $10 \mathrm{mMdNTP}$ mix, $5.0 \mu \mathrm{L}$ of $25 \mathrm{mM} \mathrm{MgCl}_{2}, 1.0 \mu \mathrm{L}$ of 5.0 Units enzyme mix, $2.0 \mu \mathrm{L}$ of 20 picomole of each outer primers (RVF1 and $\mathrm{RVF} 2), 5.0 \mu \mathrm{L}$ of target RNA were used. The total volume was brought to $50.0 \mu \mathrm{L}$ using Rnase free water. Target genes were amplified in low-profile $0.2 \mathrm{~mL}$ tube (MJ Research, California, USA). Dengue virus and CCHFV templates and total nucleic acid extracted from vero cells were used as negative controls. The cycling program consists of a reverse transcription step at $50^{\circ} \mathrm{C}$ for $30 \mathrm{~min}$. A pre-denaturation step at $95^{\circ} \mathrm{C}$ for $15 \mathrm{~min}$ was performed to inactivate excess RT enzyme and to activate the Taq DNA polymerase in the enzyme mix. This was followed by 40 cycles of denaturation at $94^{\circ} \mathrm{C}$ for $1 \mathrm{~min}$, annealing 
temperatures at $56^{\circ} \mathrm{C}$ for $30 \mathrm{sec}$ each, extension at $72^{\circ} \mathrm{C}$ for $45 \mathrm{sec}$. The reaction mixture in each $\mathrm{PCR}$ tube was then subjected to a final extention step at $72^{\circ} \mathrm{C}$ for $10 \mathrm{~min}$. All PCR amplifications were carried out at a $50 \mu \mathrm{L}$ volume per tube. Thermal profiles were performed on a Techne PHC-2 thermal cycler (Techne, Princeton, New Jersey, USA).

Following amplification, $10 \mu \mathrm{L}$ from each PCR tube containing amplified product were loaded onto gels of $1.5 \%$ SeaKem agarose (FMC Bioproduct, Rockland, Maryland, USA) and electrophoresed. The gels were stained with ethidium bromide and the PCR products were visualized under UV light.

\section{RESULTS AND DISCUSSION}

The RT-PCR provided sensitive and specific detection of RVFV in cell culture and directly in serum samples from infected humans. The pair of primers, designed from the L RNA segment produced a 384 bp primary PCR product from $\geq 100$ fg RNA of RVFV. The DNA band at $100 \mathrm{fg}$ dilution is faint but is still visible. The PCR amplification products were visualized onto an ethidium bromide-stained agarose gels (Fig. 1). Application of this RT-PCR to $1.0 \mathrm{pg}$ of RVFV RNA target resulted in direct detection of RVFV infection in acute phase sera collected from infected humans in RVFV-infected cell culture (Fig. 2).

The specificity studies indicated that the specific $342 \mathrm{bp}$ PCR products were not amplified from $1.0 \mathrm{pg}$ RNA extracted from, closely related hemorrhagic fever viruses, dengue virus RNA; Crimean Congo Hemorrhagic Fever Virus (CCHFV) RNA and total nucleic acid extracts from non infected Vero cells (Fig. 3).

Rift Valley Fever (RVF) is an infectious non contagious disease of live stock characterized by sweeping and abortion storms. Humans are also susceptible to infection and hence infection with the virus is of public health importance. Clinical manifestations of RVF are indistinguishable from those caused by other viral hemorrhagic fever viruses and hence cannot reliably identify infected patients (Meegan et al., 1987; Ashmaig et al., 2008). Viremia in infected following infection with RVFV is well documented which provides virus for vector transmission to more susceptible populations. In Sudan, RVF is of concern to public health officers because of outbreaks of the disease among human populations. The disease is also of concern to dairy producers and wildlife managers because of a possible epizootic among susceptible domestic livestock and wildlife populations (Eisa and Obeid, 1977). In the present study, researchers developed and evaluated RT-PCR for direct detection of RVFV in cell culture and

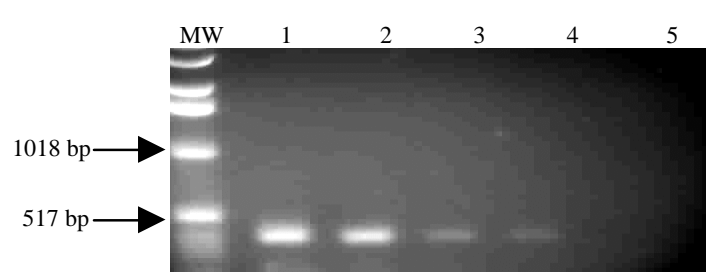

Fig. 1: Sensitivity of the RT-PCR for detection of the $384 \mathrm{bp} \mathrm{PCR}$ product using the outer pair of primers (RV1 and RV2). MW: Molecular Weight marker; Lane (1-4): RVFV RNA extracted from infected human sera at concentrations of $10 \mathrm{pg}, 1 \mathrm{pg}, 100$ $\mathrm{fg}, 1.0 \mathrm{fg}$, respectively; Lane 5: total nucleic acid extracted from non-infected Vero cells (negative control sample)

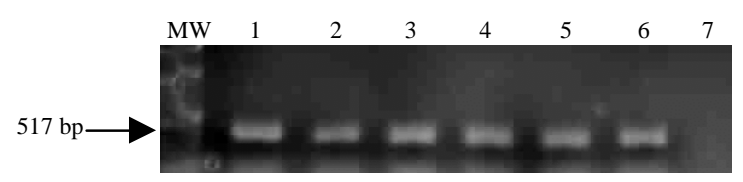

Fig. 2: RT-PCR for detection of the $384 \mathrm{bp} \mathrm{PCR} \mathrm{product} \mathrm{of}$ RVFV from different strain of the virus. The RT-PCR detected different strains of RVFV. Molecular weight marker. Lane (1-6): RVFV RNA extracted from RVFV infected human serum samples. Lane 7: total nucleic acid extracted from non-infected Vero cells (negative control)



Fig. 3: Specificity of the PCR for detection of the primary 38442 bp PCR product from RVFV. MW: Molecular Weight marker; Lane 1: RNA extracted from RVFV vaccine strain (positive control); Lane 2: RNA extracted from dengue fever virus; Lane 3: RNA Extracted from Crimean Congo hemorrhagic fever; Lane 4: non-infected Vero cells; RNA-free sample (negative controls)

serum samples from humans. The specificity studies indicated that the specific 384 bp PCR product was not amplified from a concentration of $1.0 \mathrm{pg}$ RNA from dengue virus; CCHF virus or total nucleic acid extracts from non infected Vero cell controls, under the same stringency condition described in this study. This RT-PCR-based assay could serve as a supportive diagnostic assay to the 
time consuming and cumbersome conventional virus isolation laboratory procedure which required high containment laboratory facilities. The rapidity, sensitivity and specificity of the RT-PCR would greatly facilitate detection of RVFV during an outbreak of the disease among humans and susceptible animals. The described RT-PCR based detection assay does not required nucleic acid hybridization confirmation which usually takes overnight. In addition, the RT-PCR could be easily performed in developing countries in East/Central Africa such like Sudan. Samples preparation and DNA extraction using QIAamp extraction kit was a simple procedure which takes half an hour. The thermal cycling profiles for amplification of the PCR products were consistently $3 \mathrm{~h}$. Running of the agarose gel and electrophoresis usually takes $1 \mathrm{~h}$. The described assay is a rapid procedure as the time required from submission of samples to final results of definitive diagnoses was consistently $5 \mathrm{~h}$. In contrast, the sensitivity studies of the conventional gel-based RT-PCR indicated that the described RT-PCR protocol was capable of detecting the amount of $1.0 \mathrm{pg}$ of total RVFV genomic ssRNA. This level of sensitivity is comparable to that of virus isolation. Nevertheless, the described conventional RT-PCR is a simple procedure that can easily be adopted in developing African countries. Further studies are currently under way to improve the sensitivity of the described RT-PCR assay to detect RVFV in a variety of clinical samples from experimentally and naturally infected animals and to evaluate its potential as a sensitive and specific diagnostic assay through comparison with current diagnostic test used for detection of RVFV.

\section{CONCLUSION}

In this study, the RT-PCR assay should be recommended for inclusion during an epidemiological survey of the disease in areas of endemicity.

\section{ACKNOWLEDGEMENTS}

The researchers would also like to thank Dr. Rehab A. Elageb, Minstry of Health, Republic of the Sudan; Mohamed Abdelrazig, Ministry of Animal Resources for providing the Smith burn vaccine strains; Dr. Abubaker Shazaly of the Department of Microbiology, University Malaya, Malaysia for providing dengue virus RNA. The researchers would also like to thank Mr. Abdalla M. Fadl elmoula for the invaluable technical assistance.

\section{REFERENCES}

Ahmad, K., 2000. More deaths from Rift valley fever in Saudi Arabia and Yemen. Lancet, 356: 1422-1422.

Aradaib, I.E., B.R. Erickson, M.E. Mustafa, M.L. Khristova, N.S. Saeed, R.M. Elageb and S.T. Nichol, 2010. Nosocomial outbreak of Crimean-Congo hemorrhagic fever, Sudan. Emerg. Infect. Dis., 16: 837-839.

Arthur, R.R., M.S. El-sharkawy, S.E. Cope, B.A. Botros and S. Oun et al., 1993. Recurrence of Rift valley fever in Egypt. Lancet, 6: 1149-1150.

Ashmaig, A., A. El-Kadarou, A.E. Karrar, H.A. Musa and H.H. Abu-Aisha et al., 2008. Hemorrhagic fever caused by rift valley fever virus: Rapid detection based on viral small (S) RNA genome segment. Int. J. Trop. Med., 3: 5-9.

Bird, B.H., J.W.K. Githinji, J.M. Macharia, J.L. Kasiiti and R.M. Muriithi et al., 2008. Multiple virus lineages sharing recent common ancestry were associated with a large rift valley fever outbreak among livestock in Kenya during 2006-2007. J. Clin. Microbiol., 82: 11152-11166.

Daubney, R., J.R. Hudson and P.C. Garnham, 1931. Enzootic hepatitis or rift valley fever. An undescribed virus disease of sheep, cattle and man from East Africa. J. Pathol. Bacteriol., 34: 545-579.

Eisa, M., E.D. Kheirelseed, A.M Shommein and J.M. Meegan, 1980. An outbreak of Rift Valley fever in the Sudan-1976. Trans. Royal Soc. Trop. Med. Hyg., 74: 417-419.

Eisa, M., and H.M.A. Obeid, 1977. Rift Valley fever in the Sudan. II. Isolation and identification of the virus from a recent epizootic in Kosti District, 1973. Bull. Anim. Hlth Prod. Afr., 24: 349-355.

Elageb, R.M., 2010. Molecular and serological studies on Rift Valley fever virus. M.Sc. Thesis, University of Khartoum, Sudan.

Espach, A., M. Romito, L.H. Nel and G.J. Viljoen, 2002. Development of a diagnostic one-tube RT-PCR for the detection of Rift Valley fever virus. Onderstepoort J. Vet. Res., 69: 247-252.

Garcia, S., J.M. Crance, A. Billecocq, A. Peinnequin, A. Jouan, M. Bouloy and D. Garin, 2001. Quantitative real-time PCR detection of Rift Valley fever virus and its application to evaluation of antiviral compounds. J. Clin. Microbiol., 39: 4456-4461.

Giorgi, C., 1996. Molecular Biology of Phleboviruses. In: The Bunyaviridae, Elliott, R.M. (Ed.). Plenum Press, New York, pp: 105-128.

Ibrahim, M.S., J.M. Turell, K.F. Knauert and R.S. Lofts, 1997. Detection of Rift Valley fever virus in mosquitoes by RT-PCR. Mol. Cell. Probes, 11: 49-53. 
Jansen van Vuren, P., A.C. Potgieter, J.T. Paweska and A.A. van Dijk, 2007. Preparation and evaluation of a recombinant Rift Valley fever virus $\mathrm{N}$ protein for the detection of $\operatorname{IgG}$ and $\operatorname{IgM}$ antibodies in humans and animals by indirect ELISA. J. Virol. Methods, 140: 106-114.

Le Roux, C.A., T. Kubo, A.A. Grobbelaar, P.J. van Vuren and J. Weyer et al., 2009. Development and evaluation of a real-time reverse transcription-loopmediated isothermal amplification assay for rapid detection of Rift Valley fever virus in clinical specimens. J. Clin. Microbiol., 47: 645-651.

Meegan, J.M. and C.L. Bailey, 1989. Rift Valley Fever. In: The Arboviruses: Epidemiology and Ecology, Vol. 4, Monath, T.P. (Ed.). CRC Press, Boca Raton, Florida, pp: $51-76$.

Meegan, J.M., R.J. Yedloutschnig, B.A. Peleg, C.J. Peters, J.S. Walker and R.F. Shope, 1987. Enzyme-linked immunosorbent assay for detection of antibodies to Rift Valley Fever in ovine and bovine sera. Am. J. Vet. Res., 48: 1138-1141.

Olaleye, O.D., O. Tomori and H. Schmitz, 1996. Rift Valley Fever in Nigeria: Infections in domestic animals. Rev. Sci. Tech., 15: 937-946.

Salim, R.W., K.M.S. Khairalla, A.A. Eljamal, A.E. Karrar and I.E. Aradaib, 2010. A single-tube RT-PCR amplification for detection of rift valley fever virus. Res. J. Med. Sci., 4: 146-151.
Sall, A.A., J. Thonnon, O.K. Sene, A. Fall and M. Ndiaye et al., 2001. Single-tube and nested reverse transcriptase-polymerase chain reaction for detection of Rift Valley fever virus in human and animal sera. J. Virol. Methods, 91: 85-92.

Sall, A.A., P.M. Zanotto, O.K. Sene, H.G. Zeller, J.P. Digoutte, Y. Thiongane and M. Bouloy, 1999. Genetic reassortment of Rift Valley Fever virus in nature. J. Virol., 73: 8196-8200.

Sall, A.A., P.M.D.A. Zanotto, P. Vialat, O.K. Sene and M. Bouloy, 1998. Origin of 1997-98 Rift Valley fever outbreak in East Africa. Lancet, 352: 1596-1597.

Shoemaker, T., C. Boulianne, M.J. Vincent, L. Pezzanite and M.M. Al-Qahtani et al., 2002. Genetic analysis of viruses associated with emergence of Rift Valley fever in Saudi Arabia and Yemen, 2000-01. Emerg. Infect. Dis., 8: 1415-1420.

Shope, R.E., C.J. Peters and J.S. Walker, 1980. Serological relation between Rift Valley fever virus and viruses of Phlebotomus fever serogroup. Lancet, 1: 886-887.

Youssef, B.Z., 2001 . Application of reverse transcriptasepolymerase chain reaction for detection of rift valley fever viral antigen from mosquito. J. Egypt Public Health Assoc., 76: 297-308. 